\title{
MEDIASI WORK ENGAGEMENT PADA PERCEIVED ORGANIZATIONAL SUPPORT YANG DIRASAKAN TERHADAP JOB SATISFACTION DAN ORGANIZATIONAL CITIZENSHIP BEHAVIOR
}

\author{
Nala Tri Kusuma ${ }^{1}$; Ignatius Soni Kurniawan ${ }^{2}$; Jajuk Herawati ${ }^{3}$ \\ Program studi manejemen Fakultas Ekonomi \\ Universitas Sarjanawiyata Tamansiswa Yogyakarta \\ E-mail : nala.kusuma@ustjogja.ac.id \\ diterima: 8/12/2020; direvisi: 30/3/2021; diterbitkan: 26/9/2021
}

\begin{abstract}
This research aims to test the mediation of work engagement between perceived organizational support toward job satisfaction and organizational citizenship behavior. This research performed on SMEs in Yogyakarta. The sampling technique used accidental sampling. The result showed that work engagement did not mediate perceived organizational support toward organizational citizenship behavior, but only work engagement mediated between perceived organizational support toward job satisfaction.
\end{abstract}

Keywords: Perceived organizational support, work engagement, job satisfaction, and organizational citizenship behavior.

\section{PENDAHULUAN}

Keberhasilan organisasi tidak hanya ditentukan oleh margin yang dihasilkan, keterlibatan karyawan didalam organisasi memiliki peranan penting dalam menjalankan operasional organisasi. Saat ini, baik perusahaan maupun Usaha Kecil dan Menengah (UKM) tidak hanya memerlukan karyawan yang memiliki skill sesuai job desk yang dibutuhkan, namun organisasi juga memerlukan karyawan yang mau terlibat untuk bekerja diluar tugas dan tanggungjawabnya tanpa mengharapkan reward atau kompensasi dari organisasi. Karyawan yang hanya melakukan tanggungjawab utamanya saja, seringkali terlihat sebagai karyawan yang rajin, namun ternyata karyawan tersebut memiliki potensi menganggur. (Kurniawan, 2018).

Penelitian ini mencoba menggunakan karyawan UKM Daerah Istimewa Yogyakarta yang memiliki kontribusi pada organisasi sehingga mampu berkreasi dengan memenuhi permintaan konsumen, mampu bersaing pada skala Nasional dan Internasional dengan menggunakan pendekatan
Organizational Citizenship Behavior (OCB) yang mempertimbangkan pentingnya memelihara karyawan handal yang mampu berkontribusi bagi organisasi serta dapat memberikan kepuasan kerja.

Perceived organizational support (POS) yang dirasakan ternyata memiliki pengaruh terhadap OCB, Saks (2006) menyatakan bahwa karyawan yang merasakan POS lebih tinggi memiliki ikatan sosial yang lebih kuat dengan organisasi, yang pada gilirannya mengarah lebih banyak pada OCB dan job satisfaction yang dirasakan. Selain POS yang dirasakan, keterlibatan karyawan dalam organsiasi juga memiliki pengaruh terhadap OCB. Karyawan yang memiliki keterlibatan yang lebih tinggi dalam kegiatan di organisasi akan melakukan perannya dalam organisasi dibanding karyawan lain yang tidak memiliki keterlibatan. Kusuma, Wiyono, \& Lukitaningsih (2021) dan Christian (2015) menyatakan bahwa perceived organizational support tidak berpengaruh signifikan terhadap job satisfaction, inkonsistensi dari penelitian terdahulu menjadi kesempatan bagi peneliti untuk 
mengisi celah dari penelitian terdahulu untuk melanjutkan penelitian. Jika peneliti sebelumnya lebih sering menerapkan teori POS dan OCB pada perusahaan swasta, BUMN atau usaha bisnis lain yang memiliki skala lebih besar, pada penelitian ini mencoba menerapkan pada UKM. POS dan OCB yang dipahami sebagai perilaku karyawan yang mampu meningkatkan efektifitas organisasi ternyata dapat diterapkan pada UKM yang belum memiliki struktur terorganisasi dengan jelas. OCB yang diterapkan pada UKM menggambarkan karyawan yang selalu memberikan kemampuan yang dimiliki agar organisasi berkembang dan mampu menjadi senjata untuk bersaing dalam kegiatan ekonomi.

\section{TINJAUAN PUSTAKA}

dalam $\begin{array}{crr}\text { Dasar teori yang } & \text { digunakan } \\ \text { penelitian } & \text { ini } & \text { adalah }\end{array}$ menggunakan teori pertukaran sosial yang dipopulerkan oleh Blau (1964) yang menyatakan bahwa ketika seorang karyawan merasa mendapatkan dukungan dari organisasi, maka karyawan tersebut akan berperilaku untuk membalas kebaikan kepada perusahaan. Karena teori pertukaran sosial ini memusatkan perhatian yang mengatur perilaku manusia dan hubungan antara individu dan kelompok.

Perceived Organizational Support (POS), POS adalah bentuk dukungan yang tidak hanya diperlukan dari organisasi, dukungan ini berasal dari organisasi, atasan dan rekan kerja. Ketika petugas kepolisian memiliki POS tinggi, berarti mereka memandang bahwa manajemen memberikan apresiasi terhadap kontribusi karyawan di organisasi (Zhang, Farh, \& Wang, 2011). Contoh yang diterapkan yaitu pada polisi dengan POS tinggi tersebut mereka memahami apa yang dibuat oleh manajemen dalam membuat keputusan yang meningkatkan kesejahteraan mereka. Zhang et al., (2011) menyatakan bahwa POS lebih tinggi di organisasi publik yang telah menerapkan NPM reformasi sebagai strategi yang transparan dan jelas, sehingga kinerja karyawan di organisasi lebih tinggi. Inilah peran manajemen untuk menentukan maksud strategis dan selanjutnya sumber daya dan indikator kinerja untuk setiap departemen untuk mencapai tujuannya. Para petugas polisi yang mengalami pengurangan sumber daya ditambah dengan ekspektasi yang meningkat dari beban kerja yang lebih besar cenderung melihat tingkat yang rendah POS, terutama di mana akuntabilitas telah 'memaksa' petugas polisi untuk menerima yang lebih tinggi beban kerja dan prosesnya tampaknya tidak transparan.

Work engagement karyawan terdiri dari tiga hal yaitu ekspresi kerja, kognitif, dan emosional dalam melaksanakan tanggungjawab, dan usaha yang dilakukan karyawan untuk menyesuaikan peran dalam organisasi (Bhatti, Alshagawi, \& Juhari, 2018). Alzyoud, Othman, \& Isa, (2017) menyatakan dengan keterikatan kerja karyawan dalam organisasi merupakan tanda dari semangat serta bentuk dedikasi yang diberikan karyawan kepada organisasi. Karyawan yang memiliki keterikatan akan merasa dirinya bermanfaat dan memiliki kepercayaan diri yang tinggi untuk berperan dalam pekerjaan dan memberikan bantuan kepada rekan kerja. Huo \& Boxall (2018) menyatakan work engagement merupakan konsep multidimensi yang mempengaruhi fisik, kognisi, dan energi emosional karyawan secara aktif.

Job satisfaction banyak digunakan pada bidang sumber daya manusia, baik untuk kepentingan internal maupun eksternal (Taba, 2006). Locke \& Latham (1990) berpendapat bahwa kepuasan kerja, adalah bentuk sikap emosional yang mengarah pada perasaan puas dan senang dari karyawan dari hasil evaluasi yang 


\section{Jurnal Ilmiah Ekonomi dan Bisnis}

Vol. 18. No.2,September 2021 : 128-136

EISSN : $2442-9813$

ISSN : 1829-9822

dilakukan oleh organisasi. Javed, Balouch, \& Hassan (2014) melakukan survei kepuasan kerja organisasi, terkait dengan bagaimana karyawan merasakan berbagai aspek pekerja, kepuasan kerja karyawan dikenal dengan assemble yang sudah sering dideskripsikan, didiskusikan dan diteliti. Ada beberapa faktor-faktor yang menentukan kepuasan kerja karyawan seperti perilaku antusias, faktor kebersihan, tanggung jawab manajerial dan lingkungan tempat kerja dengan membangun teori yang berbeda (Ahsan, Abdullah, Fie, \& Alam, 2009). Berdasarkan teori Maslow beliau meneliti bahwa kepuasan karyawan akan terjadi ketika apa yang dibutuhkan oleh manusia terpenuhi seperti kebutuhan dasar dan berakhir pada tingkat aktualisasi diri (Taormina \& Gao, 2013)

OCB karyawan merupakan bentuk sikap yang ditunjukkan oleh karyawan dalam menjalankan tugas dan tanggungjawabnya di luar tugas tanggungjawab formal yang telah ditentukan oleh organisasi. (Bateman \& Organ, 1983). Karyawan yang menanamkan dirinya dengan memiliki sikap OCB secara tidak langsung akan bekerja secara extra-role namun in-role. Berdasarkan penelitian terdahulu menurut Van Dyne, Graham, \& Dienesch (1994) memperjelas bahwa bentuk OCB dibagi menjadi 3 yaitu obedience, loyalty, dan participation. Sedangkan Podsakoff et al. (2000) menyatakan OCB dalam 7 bentuk, yaitu helping, sportsmanship, loyalty, organizational compliance, individual initiative, civic virtue, self development. Organ (1998); Dunlop dan Lee (2004) menyatakan bahwa dengan adanya sikap OCB yang tertanam dari diri karyawan di organisasi dapat menciptakan suasana kerja yang lebih maksimal.

POS dinilai sebagai jaminan yang tersedia dari organisasi untuk melaksanakan pekerjaan secara efektif dan menangani situasi stres kerja pada karyawan (Zhang et al., 2011). Kondisi organisasi yang mensupport, memotivasi karyawan untuk mencoba hal baru serta mengurangi kegagalan yang terjadi pada karyawan. Karyawan pada organisasi yang merasakan dukungan POS yang tinggi akan merasa terikat dengan UKM sebagai bentuk norma timbal balik (Charoensukmongkol, Moqbel, \& Gutierrez-Wirsching, 2010). Dengan kata lain, saat karyawan mempercayai adanya dukungan organisasi yang peduli tentang kesejahteraan mereka, karyawan akan cenderung menanggapinya dan melaksanakan kewajiban mereka dengan terlibat kepada organisasi (Saks, 2006).

H1: POS berpengaruh positif terhadap work engagement.

Semakin banyak organisasi yang menyadari pentingnya karyawan untuk memiliki work engagement dalam pekerjaan dan organisasinya ternyata dapat berpengaruh pada kepuasan karyawan sendiri (Lynn Barden, 2018). Work engagement karyawan dianggap sebagai strategi retensi penting karena karyawan yang terlibat mengabdikan diri pada tujuan yang ditugaskan kepada mereka. Seorang karyawan yang memiliki sikap work engagement dalam organisasi dan berpengaruh pada kepuasan kerjanya akan terlihat antusias, berkomitmen, memiliki visi dan misi, serta memiliki kesesuaian nilai organisasi. Lynn Barden (2018) ini pernah melakukan penelitian yang sama dengan melihat hubungan yang dirasakan antara work engagement dengan kepuasan kerja di Administrasi Jaminan Sosial dengan menggunakan data arsip yang dikumpulkan dari 2004 hingga 2017. Work engagement karyawan diproyeksikan menjadi prediktor kepuasan kerja.

H2: Work Engagement berpengaruh positif terhadap job satisfaction.

Saks (2006) menjelaskan keterlibatan karyawan dalam organisasi terbagi menjadi tiga faktor yaitu semangat, dedikasi, dan daya serap. 
Semangat berhubungan dengan hal positif pada pengaruh karyawan yang ditandai dengan energi positif, keuletan dalam bekerja, dan kemauan untuk menginvestasikan waktu dan tenaga dalam penugasan pekerjaan. Dedikasi terkait dengan kondisi dimana karyawan merasakan pekerjaannya untuk memperoleh kebermaknaan. Penyerapan mengacu pada aspek kognitif di mana karyawan menemukan pekerjaan mereka menyenangkan, penuh konsentrasi, dan tertanam.

Kurniawan (2018) menyatakan bahwa karyawan yang memiliki sikap work engagement akan secara sukarela untuk bekerja di waktu ekstra, dan untuk memaksimalkan pengetahuan dan energi yang dimiliki. Sedangakan Ayu Putu Widani Sugianingrat et al., (2019) mengemukakan bahwa work engagement akan cenderung membuat karyawan mengambil inisiatif secara individu mempengaruhi peran ekstra di organisasi.

H3: Work engagement berpengaruh positif terhadap OCB.

Job satisfaction merupakan faktor yang berpengaruh pada setiap kegiatan organisasi, kepuasan yang terjadi didalam organisasi dikaji melalui proses evaluasi kerja karyawan serta kesan yang didapat oleh karyawan terhadap sikap positif yang dirasakan terhadap perilaku baik dari rekan kerja, atasan maupun organisasi itu sendiri (Javed et al., 2014).

Pengawasan yang diberikan oleh atasan kepada karyawan juga merupakan bentuk dukungan yang diberikan, bentuk pengawasan tersebut menjadi simbol bahwa atasan mereka peduli terhadap kinerja yang dihasilkan, atasan mampu mengevaluasi kerja mereka yang menjadi bentuk bahwa atasan menghargai segala bentuk tanggungjawab yang sudah dikerjakan oleh karyawan. Seorang karyawan dalam organisasi tidak hanya menilai kepuasan dan loyalitas mereka hanya melalui dukungan organisasi saja, dukungan organisasi menjadi faktor penting untuk meningkatkan keyakinan karyawan bahwa organisasi peduli menghargai mereka dilihat dari kontribusi dan kepedulian mereka tentang kesejahteraan mereka (Mayes, Finney, Johnson, Shen, \& Yi, 2017), POS memiliki peranan untuk mempengaruhi kinerja karyawan terhadap kepuasan kerja (Maden \& Kabasakal, 2014).

H4: Perceived organizational support berpengaruh positif terhadap Job satisfaction

Teori tentang pertukaran sosial dapat dirasakan ketikan seorang pemimpin dalam organisasi mendukung dan percaya kepada karyawan sehingga menumbuhkan respon yang positif antara pimpinan organisasi dan karyawan (Khan, Mahmood, Kanwal, \& Latif, 2015). Bentuk hubungan timbal balik yg dilakukan oleh karyawan terhadap organisasi dengan cara yang menguntungkan dan mendukung hal itu yang sering disebut sebagai OCB (Kartika, Kaihatu, Adiwijaya, \& Nugroho, 2017). Seorang karyawan dalam organisasi tidak hanya menilai kepuasan melalui dukungan atasan ditempat mereka bekerja, perceived organizational support juga menjadi dasar karyawan untuk terikat dalam pekerjaan (Xiao, Wang, Li, \& Ma, 2017). OCB mengacu pada perilaku terkait pekerjaan yang melampaui tugas utama karyawan yang sudah ditentukan, bentuk OCB yang diberikan yaitu memberikan bantuan ekstra kepada rekan kerja, tepat waktu, dan membuat saran ketika masalah muncul. Penelitian terdahulu menunjukkan bahwa karyawan yang melaporkan POS lebih tinggi memiliki ikatan sosial yang lebih kuat dengan organisasi, yang pada gilirannya mengarah ke lebih banyak OCB (Wong \& Ngo, 2012; Newman, Nielsen and Miao, 2015). 
Jurnal Ilmiah Ekonomi dan Bisnis

Vol. 18. No.2,September 2021 : 128-136

EISSN : $2442-9813$

ISSN : $1829-9822$

H5: Perceived organizational support berpengaruh positif terhadap OCB.

\section{METODE PENELITIAN}

Populasi yang digunakan adalah Usaha Kecil Menengah (UKM), sampel yang dipilih adalah UKM di Yogyakarta berjumlah 100 responden. Teknik pengambilan sampel yang dilakukan menggunakan accidental sampling. Indikator dalam penelitian ini mengadopsi dari penelitian perceived organizational support (Huo \& Boxall, 2018); work engagement (Oliveira \& Camargo, 2016); organizational citizenship behavior (Shim \& Rohrbaugh, 2014); dan job satisfaction (Crow, Lee \& Joo, 2012).

Penentuan ukuran sampel menggunakan Rumus Slovin:

$\mathrm{n}=\frac{N}{1+N e^{2}}$

$\mathrm{n}=\frac{125}{1+125.0,05^{2}}$

$\mathrm{n}=95$

Keterangan: $\mathrm{n}=$ Ukuran sampel; $\mathrm{N}=$ Populasi; $\mathrm{E}=$ Nilai presisi (tingkat kepercayaan $95 \%$ maka e 5\%).

\section{HASIL DAN PEMBAHASAN}

Karyawan yang bekerja pada UKM di Yogyakarta lebi di dominasi dengan wanita (60\%), hampir semua karyawan di Yogyakarta adalah lulusan S1 $(39 \%)$, berdasar usia didominasi 2030 tahun $(71 \%)$, dan memiliki pengalaman bekerja 1-5 tahun (65\%). Karateristik Responden

\begin{tabular}{lll}
\hline Karakteristik & Keterangan & \% \\
\hline \multirow{3}{*}{ Gender } & Pria & 40 \\
& Wanita & 60 \\
Pendidikan & SLTP & 7 \\
& SLTA & 37 \\
& Diploma & 17 \\
& S1 & 39 \\
& Kurang daro 20 tahun & 3 \\
& 20-30 tahun & 71 \\
Usia & 31-40 tahun & 9 \\
& 41-50 tahun & 10 \\
& Diatas 50 tahun & 7 \\
& $1-5$ tahun & 65 \\
Masa Kerja & 6-10 tahun & 15 \\
\hline
\end{tabular}

Outer loading menunjukkan bahwa POS (0.9067 s.d 0.9222), work engagement (0.8493 s.d 0.8602), job satisfaction (0.8692 s.d. 0.9308), dan $O C B$ (0.8688 s.d 0.8870). Uji validitas dengan melihat AVE menghasilkan POS (0.8362), work engagement (0.7306), job satisfaction (0.8110), dan $O C B(0.7713)>0.5$, hal ini menunjukkan bahwa semua indikator memenuhi syarat. Composite Reliability POS (0.9108), work engagement (0.8443), job satisfaction (0.8955), dan $O C B$ (0.9100)>0.7. Cronbach's Alpha Based on Standardized Items POS (0.8045), work engagement (0.6314), job satisfaction (0.7718), dan $O C B$ (0.8524)> 0.6 atau instrumen reliabel. Dari tabel tersebut terlihat bahwa semua skor variabel laten melewati kriteria minimum. Oleh karena itu, masing-masing indikator dari variabel latennya memiliki tingkat realibilitas dan validitas tinggi.

Tabel 2 menunjukkan hasil uji hipotesis. Dilihat dari tabel tersebut, pengujian $\mathrm{H} 1, \mathrm{H} 2, \mathrm{H} 4$, dan $\mathrm{H} 5$ diterima dengan nilai sig. $<0.05, \mathrm{H} 3$ ditolak karena nilai sig. $>0.05, \mathrm{H} 3$ diterima sig. $<0.05$.

\begin{tabular}{|c|c|c|c|}
\hline \multicolumn{4}{|c|}{ Path Coefficients } \\
\hline & $\begin{array}{c}\text { Original } \\
\text { Sample }(O)\end{array}$ & $\begin{array}{c}\text { Standard } \\
\text { Deviation } \\
(\text { STDEV) }\end{array}$ & $P$ Values \\
\hline$P O S-W E$ & 0.3790 & 0.0781 & 0.0000 \\
\hline$W E-J S$ & 0.1725 & 0.0841 & 0.0407 \\
\hline$W E-O C B$ & 0.0262 & 0.1016 & 0.7970 \\
\hline$P O S-J S$ & 0.5393 & 0.1005 & 0.0000 \\
\hline$P O S-O C B$ & 0.4863 & 0.0892 & 0.0000 \\
\hline
\end{tabular}

$\mathrm{POS}=$ Perceived organizational support; $\mathrm{WE}=$ Work Engagement; $\mathrm{OCB}=$ Organizational citizenship behavior; JS=Job Satisfaction

Sumber: Data Primer, diolah 2020

Hasil Sobel test (Gambar 1) menghasilkan nilai one tailed probability sebesar 0.0294 dengan tingkat signifikansi $5 \%$ yang membuktikan bahwa variabel work engagement memediasi POS terhadap job satisfaction. Hasil perhitungan Sobel test (Gambar 2) menunjukkan nilai one tailed probability sebesar 0.00 dengan tingkat signifikansi $5 \%(0.00<0.05)$ yang membuktikan bahwa variabel work engagement memediasi pengaruh POS terhadap OCB. 


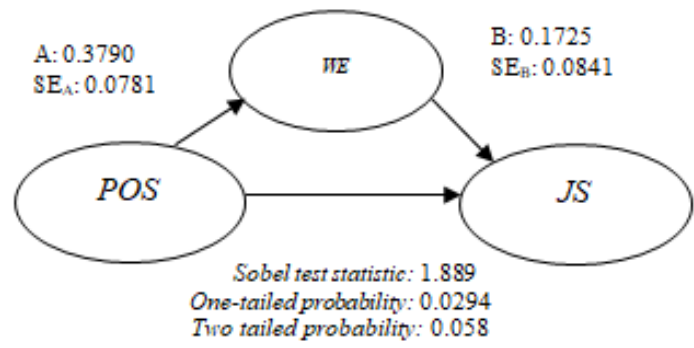

Gambar Mediasi 1

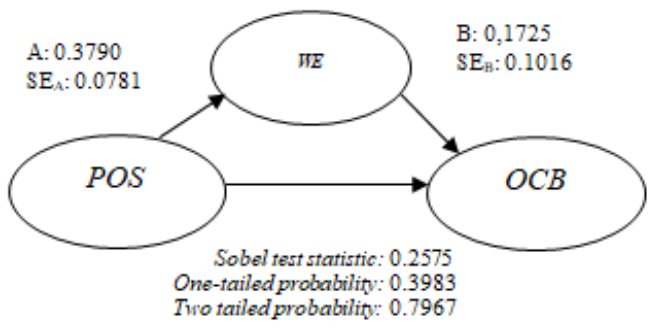

Gambar Mediasi 1

Hipotesis 1, POS memiliki pengaruh positif dan signifikan terhadap work engagement. Temuan ini mengkonfirmasi penelitian dari Saks (2006). Implementasi POS menggambarkan organisasi selalu memberikan bentuk respon yang baik terhdap karyawannya tidak hanya dalam bentuk gaji, upah, maupun reward, namun diberikan dalam bentuk dukungan yang diberikan dari organisasi, atasan serta rekan kerja. Indikator POS yang memiliki nilai rerata rendah terdapat pada item indikator "Dukungan terhadap rekan kerja" (rerata $=11.13$ ), dan "Dukungan organisasi" (rerata $=20.09$ ). Indikator yang memiliki nilai tertinggi terdapat pada "Dukungan atasan (rerata=27.03).

Hipotesis 2, diterima. Temuan ini mengkonfirmasi penelitian yang dilakukan oleh Lynn Barden (2018) bahwa work engagement berpengaruh positif terhadap job satisfaction. Seorang karyawan yang memiliki keterlibatan kerja di dalam organisasi dan memiliki kepuasan kerja akan terlihat berbeda dibandingkan karyawan lainnya, mereka akan terlihat lebih antusias, berkomitmen, memiliki visi dan misi, serta memiliki kesesuaian nilai organisasi.
Work engagement tidak berpengaruh signifikan terhadap OCB. Penelitian ini tidak mendukung penelitian yang dilakukan oleh Ayu Putu Widani Sugianingrat et al., (2019). Indikator work engagement yang dinilai rendah yaitu "Keterikatan kognitif'(rerata $=24.25)$, dan keterikatan emosional (rerata $=25.25)$ masih dapat ditingkatkan, sedangkan indikator dengan nilai tertinggi adalah keterikatan fisik $($ rerata $=25.25)$.

POS berpengaruh positif dan signifikan terhadap job satisfaction pada karyawan. Penelitian ini mengkonfirmasi hasil dari Maden \& Kabasakal (2014).yang menyatakan bahwa kepuasan karyawan didalam organisasi terjadi melalui proses evaluasi kerja yang diadakan oleh organisasi serta kesan positif yang dirasakan terhadap perilaku baik dari rekan kerja, atasan maupun organisasi itu sendiri. Semakin tinggi bentuk POS yang diberikan karyawan maka akan semakin puas sikap karyawan kepada perusahaan. Bentuk job satisfaction karyawan akan merespon karyawan untuk lebih memberikan kemampuan yang dimiliki secara totalitas pada pekerjaannya.

Hipotesis 5, menghasilkan temuan bahwa POS berpengaruh positif dan signifikan terhadap OCB. Temuan penelitian sesuai dengan yang dilakukan oleh Wong \& Ngo (2012); Newman, Nielsen \& Miao (2015). Indikator dari OCB yang perlu ditingkatkan "Alturisem" $($ rerata $=3.60)$, dan "Civic virtue (rerata= 7.01), serta indikator yang tetap dipertahankan "Extra role" (rerata=7.24).

\section{KESIMPULAN DAN SARAN}

Temuan penelitian menyatakan POS berpengaruh terhadap work engagement, POS dan work engagement berpengaruh terhadap job satisfaction, POS berpengaruh terhadap OCB, sedangkan work engagement tidak berpengaruh terhadap OCB Temuan berimplikasi agar organisasi dapat meningkatkan item work engagement yang masih rendah pada 
Jurnal Ilmiah Ekonomi dan Bisnís

Vol. 18. No.2,September 2021 : 128-136

EISSN : $2442-9813$

ISSN : $1829-9822$

karyawan sehingga dapat menumbuhkan sikap OCB pada karyawan. Hasil uji sobel test 1 menghasilkan bahwa work engagement mampu memediasi POS terhadap job satisfaction yang menandakan bahwa dukungan organisasi yang diberikan semakin dirasakan akan mendorong karyawan untuk terlibat dalam pekerjaan yang membentuk sikap OCB karyawan pada organisasi.

Penelitian selanjutnya dapat menggunakan referensi variabel lain seperti: Reward recognition (Sinnappan \& Amulraj, 2014); autonomy dan feedback from job (Shantz, Alfes, Truss, \& Soane, 2013).

\section{DAFTAR PUSTAKA}

Ahsan, N., Abdullah, Z., Fie, D. Y. G., \& Alam, S. S. (2009). sA study of job stress on job satisfaction among university staff in Malaysia: Empirical study. European Journal of Social Sciences, 8(1), 121-131.

Alzyoud, A. A. Y., Othman, S. Z., \& Isa, M. F. M. (2017). Examining the Role of Job Resources on Work Engagement in the Academic Setting. Asian Social Science, 11(3), 103-110.

https://doi.org/10.5539/ass.v11n3p10 3

Ayu Putu Widani Sugianingrat, I., Rini Widyawati, S., Alexandra de Jesus da Costa, C., Ximenes, M., Dos Reis Piedade, S., \& Gede Sarmawa, W. (2019). The employee engagement and OCB as mediating on employee performance. International Journal of Productivity and Performance Management, 68(2), 319-339. https://doi.org/10.1108/IJPPM-032018-0124

Bateman, T. S., \& Organ, D. W. (1983). Job Satisfaction and the good soldier: The relationship between Affect and Employee "Citizenship." Academy of Management Journal, 26(4), 587595. https://doi.org/10.5465/255908
Bhatti, M. A., Alshagawi, M., \& Juhari, A. S. (2018). Mediating the role of work engagement between personal resources ( self-efficacy, the big five model ) and nurses ' job performance. International Journal of Human Rights in Healthcare, 11(3), 176-191. https://doi.org/10.1108/IJHRH-102017-0056

Blau, P. (1964). Exchange and power in social life. California: Stanford University Press.

Charoensukmongkol, P., Moqbel, M., \& Gutierrez-Wirsching, S. (2010). The role of co-worker and supervisior support on job burnout and job satisfaction. The Eletronic Library, 34(1),

$1-5$. https://doi.org/https://doi.org/10.1108/ JAMR-06-2014-0037

Christian, L. Y. (2015). Pengaruh perceived organizational support dan kepemimpinan situational terhadap kepuasan kerja Toko Buku Uranus. Agora, 3(1), 442-449.

Crow, M. S., Lee, C., \& Joo, J. (2012). Organizational justice and organizational commitment among South Korean police officers. An investigation of job satisfaction as a mediator. Policing: An International Journal of Police Strategies \& Management, 35(2), 402-423. https://doi.org/10.1108/136395112112 30156

Huo, M.-L., \& Boxall, P. (2018). Are all aspects of lean production bad for workers? an analysis of how problemsolving demands affect employee well-being. Human Resource Management Journal, 28(4), 569-584. https://doi.org/10.1111/17488583.12204

Javed, M., Balouch, R., \& Hassan, F. (2014). Determinants of job satisfaction and its impact on employee performance and turnover intentions. International Journal of Learning and Development, 4(2), 120 
140.

https://doi.org/10.5296/ijld.v4i2.6094

Kartika, E. W., Kaihatu, T. S., Adiwijaya,

M., \& Nugroho, A. (2017). Perceived

Supervisor Support (PSS), Affective Commitment, and Organizational Citizenship Behavior (OCB): Study in Indonesian Context. Sustainable Entrepreneurial Organization. Paper Presented at ICOEN The 3rd International Conference on Entrepreneurship. Surayabay: Universitas Ciputra, 180-192.

Khan, S., Mahmood, A., Kanwal, S., \& Latif, Y. (2015). How perceived supervisor support effects workplace deviance? Mediating role of perceived organizational support. Pakistan Journal of Commerce and Social Sciences (PJCSS), 9(3), 940967.

Kurniawan, I. S. (2018). Analisis pengaruh penggunaan instagram, pengalaman praktik kewirausahaan, dan hasil belajar kewirausahaan terhadap minat berwirausaha online. Akmenika, 15(2), 135-146. Retrieved from

https://journal.upy.ac.id/index.php/ak menika/article/view/1003

Kusuma, N. T., Wiyono, G., \& Lukitaningsih, A. (2021). Faktorfaktor yang mempengaruhi organizational citizenship behavior pada karyawan swasta di Provinsi Yogyakarta. Jurnal Bingkai Ekonomi, 6(1), 16-26. Retrieved from

http://itbsemarang.ac.id/jbe/index.ph p/jbe33/article/view/91

Locke, E. A., \& Latham, G. P. (1990). Work Motivation and satisfaction: Light at the end of the tunnel. Psychological Science, 1(4), 240 246.

Lynn Barden, C. (2018). The correlation between employee engagement and job satisfaction in the social security administration. Journal of Business
\& Economics Research (JBER), 8(9), 1-73. Retrieved from https://opus.govst.edu/capstones://opus .govst.edu/capstones/365

Maden, C., \& Kabasakal, H. (2014). The simultaneous effects of fit with organizations, jobs and supervisors on major employee outcomes in Turkish banks: Does organizational support matter? International Journal of Human Resource Management, 25(3), 341-366.

https://doi.org/10.1080/09585192.2013 .789446

Mayes, B. T., Finney, T. G., Johnson, T. W., Shen, J., \& Yi, L. (2017). The effect of human resource practices on perceived organizational support in the People's Republic of China. International Journal of Human Resource Management, 28(9), 12611290.

https://doi.org/10.1080/09585192.2015 .1114768

Newman, A., Nielsen, I., \& Miao, Q. (2015). The impact of employee perceptions of organizational corporate social responsibility practices on job performance and organizational citizenship behavior: evidence from the Chinese private sector. International Journal of Human Resource Management, 26(9), 12261242.

https://doi.org/10.1080/09585192.2014 .934892

Oliveira, C. De, \& Camargo, C. (2016). Social connection in organizations: The effects of local ties on job engagement and performance. Management Journal, 51, 377-385. https://doi.org/http://dx.doi.org/10.101 6/j.rausp.2016.07.005

Saks, A. M. (2006). Antecedents and consequences of employee engagement. Journal of Managerial Psychology, 21(7), 600-619. https://doi.org/10.1108/026839406106 90169 
Jurnal Ilmiah Ekonomi dan Bisnis

Vol. 18. No.2,September 2021 : 128-136

EISSN : $2442-9813$

Shantz, A., Alfes, K., Truss, C., \& Soane, E. (2013). The role of employee engagement in the relationship between job design and task performance, citizenship and deviant behaviours. The International Journal of Human Resource Management, 24(13), 2608-2627. https://doi.org/10.1080/09585192.20 12.744334

Sinnappan, L. P., \& Amulraj, M. (2014). Impact of rewards and recognition and empowerment on organizational citizenship behaviors among technical engineers. Management Studies and Economic Systems, 1(2), 89-95.

https://doi.org/10.12816/0006208

Taba, I. M. (2006). Mediating effect of work performance and organizational commitment in relationship between reward system to employees' work satisfaction. Journal of Management Development, 25(8), 1-12. https://doi.org/10.1108/jmd.2006.026 25haa.001

Taormina, R. J., \& Gao, J. H. (2013). Maslow and the motivation hierarchy: Measuring satisfaction of the needs. American Journal of Psychology, 126(2), 155-177. https://doi.org/10.5406/amerjpsyc. 12 6.2.0155

Van Dyne, L., Graham, J. W., \& Dienesch, R. M. (1994). Organizational citizenship behavior: Construct redefinition, measurement, and validation. Academy of Management Journal, 37(4), 765802. https://doi.org/10.5465/256600

Xiao, H., Wang, Y., Li, W., \& Ma, Z. (2017). Nankai Business Review International Article information. Nankai Business Review International, $\quad 8(1), \quad$ 100-120. https://doi.org/10.1108/NBRI-102016-0035

Yui-Tim Wonga, C.-S. W. \& H.-Y. N. (2012). The effects of trust in organisation and perceived organisational support on organisational citizenship behaviour: A test of three competing models. International Journal of Human Resource Management, 23(2), 278293.

https://doi.org/10.1080/09585192.2011 .610966

Zhang, Y., Farh, J. L., \& Wang, H. (2011). Organizational antecedents of employee perceived organizational support in China: A grounded investigation. The International Journal of Human Resource Management, 23(2), 422-446. https://doi.org/10.1080/09585192.201 1.560886 